\title{
ELDERLY PEOPLE'S FUNCTIONAL STATE OF MUSCULOSKELETAL SYSTEM CORRECTION BY EASTERN METHODS
}

\author{
${ }^{1}$ Petrushkina Nadezhda, ${ }^{2}$ Kolomietc Olga, ${ }^{3}$ Plachy Judit \\ ${ }^{1,2}$ The Ural State University of Physical Culture, Chelyabinsk, Russia \\ ${ }^{3}$ University of Miskolc, Faculty of Health Care, Miskolc, Hungary
}

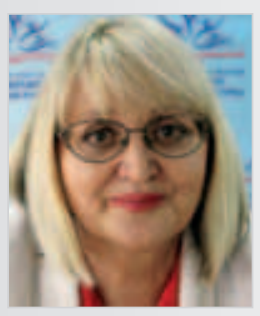

Szerzo":

PETRUSHKINA NADEZHDA

Department of Physiology

25ppnn@mail.ru

Technologies and management of physical recreation at different ontogenesis stages Sport physiology, sportsmen's physical rehabilitation technologies and management

Technologies and management of people's, having health problems, physical rehabilitation

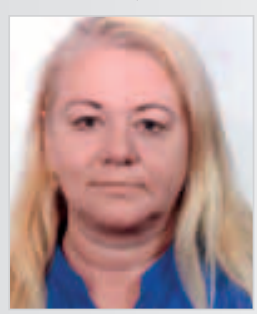

Szerzo" / rovatvezető: DR. K. PLACHY JUDIT Munkahely: Miskolci Egyetem Egészségügyi Kar Fizioterápiás Intézeti Tanszék - adjunktus efkplachy@uni-miskolc.hu Érdeklődési kör: fizikai rekreációs foglalkozások tartása minden korosztály, leginkább a nyugdíjas lakosság számára.

\section{ABSTRACI}

The problem of aging and associated degenerative changes in human organism state general and the musculoskeletal system in particular remains relevant.

10 elderly age women took part in the research in the experimental group. All subjects for several years suffered from periodic pain in the large joints and in different parts of the spine, which increased during movement. The average age of the subjects was 62.1 years.

During the session, all the joints from the head to the toes were worked out, the muscles of the whole body warm up. When exposed to the abdominal cavity, there is spasms and stagnation removal, internal organs normalization. The session ends with relaxing exercises for head and neck muscles. The overall effect after the session is characterized by the following changes.

The research results are presented in tables and figures. The presented data indicate a positive (statistically significant) dynamics of the studied characteristics, which confirms effectiveness of the proposed methodology for this contingent.

Regarding positive results it is planned to continue the research and study of the Eastern technologies influence over functional and psycho-emotional state.

\section{RATIONALE}

To solve the problem of preservation and strengthening of population health is very important; it is one of the most important conditions of state development. The fact is confirmed by development of national programs for strengthening population health. Special attention is paid to the elderly, as while maintaining their health, their age of working capacity increases and serious diseases leading to disability, occur later ( $R F$ Government Regulation 2017).
In elderly and senile age, dysfunction of the musculoskeletal system is more often recorded, which are manifested by the following morphofunctional changes: joints and vertebral discs thinning; constant pain syndrome; spine curvature, posture and gait disorders; individual bones deformation; increasing bone fragility and reducing their ability to recover from injuries (Baybulatova L. F. 2016; Jean Louise, 2017).

The program of physical rehabilitation for elderly people uses several main directions (Evseeva O. E. 2016; Grigorishina T. I. 2017): physical health restoration (remedial gymnastics, ergotherapy); creative (artistic, musical); bodily-oriented adaptive physical education; massage treatments and body-oriented technologies; kinesiotherapy; herbal medicine; psychotherapy; orthopedic services (prosthetics); use of technical rehabilitation means and treatment at specialized resorts. Based on the above, taking into account the practical significance of the research problem, the aim of the research was determined: to experimentally assess the effectiveness of Eastern body-oriented technologies (EBOT) use to improve elderly people's musculoskeletal system.

\section{RESEARCH ORGANISATION AND METHODS}

All experimental procedures and protocols were approved by the Ethics Committee of the Ural State University of Physical Culture. Oral and written consents were obtained voluntarily from all subjects prior to participation. The research met the standards set out in the Helsinki Declaration (Bykov, E. V. 2019).

10 elderly age women took part in the research in the experimental group. All subjects for several years suffered from periodic pain in the large joints and in different parts of the spine, which increased during movement. The average age of the subjects was 62.1 years. 
To improve the condition of the observed women we used sessions of Eastern bodily-oriented technologies with elements of stretching and balance exercises (Marika Giardini, 2018). Stretching technology was selected as the most appropriate for the underlying problems of this contingent. The method is based on the recommendations of the UK's largest organization dedicated to health care (https://www.nhs.uk/ live-well/exercise/flexibility-exercises/). The main purpose of this complex is to reduce the causes of functional disorders, which, over time, can lead to chronic diseases, as well as to prevent or slow the progression of existing diseases (L. Bulanov, 2011; E. Ladygina, O. E. Evseeva, 2017).

During the session, all the joints from the head to the toes were worked out, the muscles of the whole body warm up. When exposed to the abdominal cavity, there is spasms and stagnation removal, internal organs normalization. The session ends with relaxing exercises for head and neck muscles. The overall effect after the session is characterized by the following changes:

- Removal of emotional and physical stress;

- Improvement of microcirculation in tissues;

- Restoration of joints mobility;

- Muscle elasticity improvement;

- Restoration of the body gravity center;

- Improving internal organs functioning;

- Uplifting and improving performance.

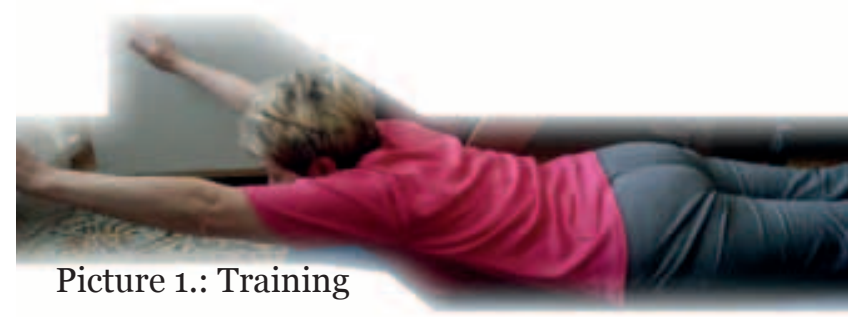

The sessions took place twice a week. One session lasted $60 \pm 5$ minutes in average; a total of 20 sessions.

To evaluate the effectiveness of the proposed method, we evaluated the dynamics of a number of subjective (pain) and objective characteristics (test results). Before the first session and after the twentieth, the subjects were interviewed to assess pain symptoms on a 10-point scale, presented in 1932 by Rensis Likert, where 1 - slight discomfort, 10 - acute pain that requires potent painkillers. At the same time some tests, showing their musculoskeletal system joints' flexibility were performed.

Dynamics of joints mobility was analyzed according to the basic joints mobility dynamics:

Test 1 - raising legs to the side, sitting on the floor (the angle between legs in degrees);

Test 2 - lifting the torso, hands elongated forward, lying on the floor, not lifting legs (angle between the floor and the hand line in degrees);

Test 3 - putting arms with a stick behind a head (wide grip) (150 cm) in standing position ( 1 - fulfilled, $\mathrm{o}$ - not fulfilled);
Test 4 - sitting on a chair, ankle joint of one foot on the other knee, the knee is lowered to the outside (knee angle in degrees)

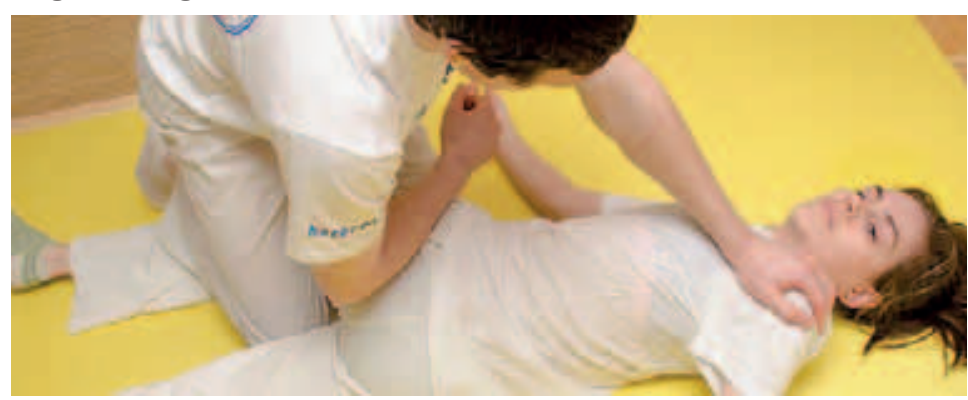

Piture2.: Test 4.

To evaluate the research result, the mean values of the test results in dynamics (before and after the experiment), mean errors and quadratic deviations were calculated. Reliability of differences was determined by Student's criterion (95\% significance level) (Bykov, E. V. 2019-a).

\section{RESEARCH RESULTS AND DISCUSSION}

The research results are presented in tables and figures. The presented data indicate a positive (statistically significant) dynamics of the studied characteristics, which confirms effectiveness of the proposed methodology for this contingent.

Statistically significant pain reduction in various parts of the spine and articular extremities both in the morning and in the afternoon was registered (Table 1). A similar picture is observed in results dynamics for tests, reflecting joint mobility (Table 2). The improvement of the musculoskeletal system can be explained by the fact that the used technology impact is not aimed at a specific part of the body or joint, in which there are pain symptoms, but at the whole body, as an interconnected single system (Petrushkina N. P. 2010).

TABLE 1 Dynamics of daily pain assessment in different parts of musculoskeletal system before and after the experiment

\begin{tabular}{|c|c|c|c|c|c|c|c|}
\hline \multirow{3}{*}{ Observation period } & \multicolumn{7}{|c|}{$\begin{array}{l}\text { Time of a day, Mid-values }(M) \text {, error in mean }(m) \\
\text { quadratic fluctuations }(\sigma) \text {, Student's criterion }(t)\end{array}$} \\
\hline & \multicolumn{3}{|c|}{ From 6 till 18 hours } & \multicolumn{3}{|c|}{ From 18 till 6 hours } & \multirow{2}{*}{$\mathrm{t}$} \\
\hline & $\mathbf{M}$ & $\mathrm{m}$ & $\sigma$ & $\mathbf{M}$ & $\mathrm{m}$ & $\sigma$ & \\
\hline \multicolumn{8}{|c|}{ Pains in cervical spine } \\
\hline Before the experiment & 5,6 & 0,43 & 1,3 & 5,2 & 0,22 & 0,65 & $\underline{10,98}$ \\
\hline After the experiment & 1,4 & $-0,11$ & $-0,32$ & 0,5 & $-0,11$ & $-0,32$ & $\underline{19,42}$ \\
\hline \multicolumn{8}{|c|}{ Pains in lumbar spine } \\
\hline Before the experiment & 6,4 & 0,32 & 0,97 & 7,2 & 0,22 & 0,65 & $\underline{12,3}$ \\
\hline After the experiment & 1,6 & 0,22 & 0,65 & 2 & 0,43 & 1,3 & $\underline{10,72}$ \\
\hline \multicolumn{8}{|c|}{ Pains in upper limbs } \\
\hline Before the experiment & 2,8 & 0,22 & 0,65 & 4,1 & 0,22 & 0,65 & $\underline{11,09}$ \\
\hline After the experiment & 0,4 & 0 & 0 & 1 & 0,22 & 0,65 & $\underline{10,13}$ \\
\hline \multicolumn{8}{|c|}{ Pains in lower limbs } \\
\hline Before the experiment & 6,8 & 0,54 & 1,62 & 5,3 & 0,32 & 0,97 & $\underline{8,75}$ \\
\hline After the experiment & 1,7 & 0,2 & 0,65 & 1,7 & 0,11 & 0,32 & $\underline{10,52}$ \\
\hline
\end{tabular}




\section{TABLE 2}

Dynamics of tests', showing changes in musculoskeletal system results before and after the experiment

\begin{tabular}{|l|c|c|c|c|c|c|c|}
\hline \multirow{4}{*}{ Tests* } & \multicolumn{6}{|c|}{$\begin{array}{c}\text { Observation period, mid-values (M), error in mean (m) } \\
\text { quadratic fluctuations ( } \sigma) \text {, Student's criterion (t) }\end{array}$} \\
\cline { 2 - 8 } & \multicolumn{2}{|c|}{ Before the experiment } & \multicolumn{3}{c|}{ After the experiment } & \multirow{2}{*}{$\mathrm{t}$} \\
\cline { 2 - 8 } & $\mathrm{M}$ & $\mathrm{m}$ & $\sigma$ & $\mathrm{M}$ & $\mathrm{m}$ & $\sigma$ & \\
\hline Test 1 & 55 & 5,41 & 16,32 & 88 & 4,33 & 12,99 & 4,76 \\
\hline Test 2 & 11 & 3,25 & 9,74 & 39 & 1,62 & 4,87 & 7,71 \\
\hline Test 3 & 0 & 0 & 0 & 0,7 & 0,11 & 0,32 & 6,47 \\
\hline Test 4 & 23,5 & 7,58 & 22,73 & 64,5 & 9,74 & 29,22 & 3,32 \\
\hline
\end{tabular}

*Notice:

Test 1 - raising legs to the side, sitting on the floor (the angle between legs in degrees);

Test 2 - lifting the torso, hands elongated forward, on the floor, not lifting legs (angle between the floor and the hand line in degrees);

Test 3 - putting arms with a stick behind a head (wide grip) $(150 \mathrm{~cm})$ in standing position ( 1 - fulfilled, o - not fulfilled);

Test 4 - sitting on a chair, ankle joint of one foot on the other knee, the knee is lowered to the outside (knee angle in degrees)

\section{CONCLUSION.}

The problem of aging and associated degenerative changes in human organism state general and the musculoskeletal system in particular remains relevant.

In this regard, the search for the problem solutions is one of the main tasks to improve the quality of elderly people's life.

The results obtained in this research work, showed a clear tendency to improve the state of joint mobility in women who participated in the experiment.

This fact confirms the effectiveness of Eastern bodily-oriented technologies elderly people's recovery, including their musculoskeletal system functions improvement.

The practical significance of the work lies in the fact that the conclusions contained in the research can serve as a basis for the introduction of EBOT to rehabilitation measures to improve elderly women's musculoskeletal system.

During the experiment, women, practicing Eastern bodily-oriented technologies, subjectively noted their cardiorespiratory function and emotional state improvement.

At this working stage, we did not register these changes and, accordingly, did not make calculations.

It is planned to continue the research and study of the Eastern technologies influence over functional and psycho-emotional state.

\section{REFERENCES:}

1. Jean Louise, R Andrew Moore, Claire Clark, Denis Martin, Leslie Colvin, Blair H. Smith. Physical activity and exercise for chronic pain in adults: a review of Cochrane reviews. Cochrane database Syst Rev. 2017 APR. 24; (4): CD011279. Published online 201724 April. Doi: 10.1002 / 14651858.CD011279.pub3 PMCID: PMC5461882.

2. Marika Giardini, Antonio Nardone, Marco godi, Simon Guglielmetti, Ilaria Arcolin, Fabrizio Pisano, Marco Skippety Instrumental or physical exercise, Restoration of balance, balance improves gait in Parkinson's disease. Neural layer. 2018; 2018: 5614242. Published online 2018 March 7. Doi: 10.1155 / 2018/5614242. PMCID: PMC5863303.

3. Baybulatova, L. F. Walking disorders of elderly people: diagnosis and integrated rehabilitation / Baybulatova, L. F., D. R. Zakirova, H. I. Mamedov, G. R. Khuzina // journal of modern clinical medicine. 2016. Vol. 9. \#. 6. P. 115-119.

4. Bulanov L. Rehabilitation with Eastern practices use. Saint-Petersburg. 2011. 130p.

5. Bykov, E. V. Methodological approaches in scientific research organization in the field of physical culture and sports/ O. I. Kolomiets, E. V. Bykov, N. P. Petrushkina, N. A. Simonova // Pedagogical-psychological and medical-biological problems of physical culture and sport. Vol. 14. \#. 1 2019. P.

a) Bykov, E. V. Features of scientific research organization in the field of physical culture and sports (work of the Ethical Committee of UralSUPC. / O. I. Kolomiets, A. N. Kovalenko, A. V. Chipyshev, O. A. Makunina // Scientific and Sport Bulletin of the Urals and Siberia. -2019.- \# 1.- Vol. 21.- P. 63-69.

6. Grigorishina T. I. Physical rehabilitation of elderly patients with gonarthrosis / T. I Grigorishina., I. V. Yarosh, V. S. Talalaev // Major scientific researches in modern world. 2017. \#. 4-3 (24). P. 108-111.

7. Evseeva O. E. Adaptive physical culture in work with the elderly/ in the collection of scientific articles: Mental health of the XXI century humans. Collection of scientific articles on the materials of the Congress. 2016. P. 411-413.

8. Ladygina E. B., Evseeva O. E. Creative (art-musical) bodily-oriented types of adaptive physical culture in elderly persons' recreational activity / in the collection of scientific articles: Adaptive physical culture and sanatorium - resort rehabilitation: innovative technologies and developmental priorities. Collection of scientific works based on the materials of the all-Russian scientific-practical conference. 2017. P. 135-142.

9. Petrushkina, N. P. Age physiology / N. P. Petrushkina, E. V. Zhukovskaya. - Chelyabinsk: Uralgufk (UralSUPC) publishing house, 2010. - 300 p.

10. 10. RF Government Regulation of December 26, 2017 N 1640 «On approval of the state program of the Russian Federation «Health preservation development»». 